\title{
Sequence length dependence in arginine/phenylalanine oligopeptides: Implications for self-assembly and cytotoxicity
}

Article

Accepted Version

Creative Commons: Attribution-Noncommercial-No Derivative Works 4.0

Silva, E. R., Listik, E., Han, S. W., Alves, W. A., Soares, B. M., Reza, M., Ruokolainen, J. and Hamley, I. W. (2018) Sequence length dependence in arginine/phenylalanine oligopeptides: Implications for self-assembly and cytotoxicity. Biophysical Chemistry, 233. pp. 1-12. ISSN 0301-4622 doi: https://doi.org/10.1016/j.bpc.2017.11.005 Available at https://centaur.reading.ac.uk/74706/

It is advisable to refer to the publisher's version if you intend to cite from the work. See Guidance on citing.

Published version at: http://dx.doi.org/10.1016/j.bpc.2017.11.005

To link to this article DOI: http://dx.doi.org/10.1016/j.bpc.2017.11.005

Publisher: Elsevier

All outputs in CentAUR are protected by Intellectual Property Rights law, including copyright law. Copyright and IPR is retained by the creators or other copyright holders. Terms and conditions for use of this material are defined in the End User Agreement. 


\section{www.reading.ac.uk/centaur}

\section{CentAUR}

Central Archive at the University of Reading

Reading's research outputs online 


\title{
Sequence Length Dependence in Arginine/Phenylalanine Oligopeptides: Implications for Self-Assembly and Cytotoxicity
}

\author{
Emerson R. Silva a,*, Eduardo Listik ${ }^{\mathrm{b}}$, Sang W. Han ${ }^{\mathrm{a}}$, Wendel A. Alves ${ }^{\mathrm{c}}$, Bruna M. \\ Soares $^{\mathrm{c}}$, Mehedi Reza $^{\mathrm{d}}$, Janne Ruokolainen ${ }^{\mathrm{d}}$ and Ian W. Hamley ${ }^{\mathrm{e}}$
}

${ }^{a}$ Departamento de Biofísica, Universidade Federal de São Paulo, São Paulo 04023-062, Brazil; ${ }^{b}$ Instituto de Ciências Biomédicas, Universidade de São Paulo, São Paulo 05508-900, Brazil; ' Centro de Ciências Naturais e Humanas, Universidade Federal do ABC, Santo André 09210-580, Brazil; 'Department of Applied Physics, Aalto University, Aalto FI-00076, Finland; ${ }^{e}$ Department of Chemistry, University of Reading, Reading RG6 6AD, United Kingdom.

\begin{abstract}
We present a detailed study on the self-assembly and cytotoxicity of arginine-rich fragments with general form $[R F]_{n}(n=1-5)$. These highly simplified sequences, containing only two $L$-amino acids, provide suitable models for exploring both structure and cytotoxicity features of arginine-based oligopeptides. The organization of the sequences is revealed over a range of length scales, from the nanometer range down to the level of molecular packing, and their cytotoxicity toward C6 rat glioma and RAW264.7 macrophage cell lines is investigated. We found that the polymorphism is dependent on peptide length, with a progressive increase in crystalline ordering upon increasing the number of [RF] pairs along the backbone. A dependence on length was also found for other observables, including critical aggregation concentrations, formation of chiral assemblies and half maximum inhibitory concentrations $\left(\mathrm{IC}_{50}\right)$. Whereas shorter peptides self-assemble into fractal-like aggregates, clear fibrillogenic capabilities are identified for longer sequences with octameric and decameric chains exhibiting crystalline phases organized into cross- $\beta$ structures. Cell viability assays revealed dose-dependent cytotoxicity profiles with very similar behavior for both glioma and macrophage cell lines, which has been interpreted as evidence for a nonspecific mechanism involved in toxicity. We propose that structural organization of $[R F]_{n}$ peptides plays a paramount role regarding toxicity due to strong increase of local charge density induced by self-assemblies rich in cationic groups when interacting with cell membranes.
\end{abstract}

Keywords: cross- $\beta$ structure, fibrillization, cytotoxicity, scattering, fiber diffraction. 
Self-assembly of oligopeptides into well-ordered nanostructures is a current topic due both to the outstanding properties of these compounds for developing new materials[1] and the involvement of peptide aggregates in several degenerative diseases.[2, 3] Designed drug carriers,[4] nucleic acid transporters[5] and biosensors[6] are among the main applications envisaged for peptide-based scaffolds.[7] In the field of clinical disorders, amyloid-related pathologies such as Alzheimer's and Parkinson's diseases are well-known examples of the role played by protein/peptide self-assembly in biological processes.[8] The polymorphism exhibited by these assemblies is complex and appears correlated to a number of factors, ranging from composition to synthesis conditions.[1] Also, the influence on living matter, especially concerning toxicity, is closely correlated to both chemical composition and structural organization.[9] Assessing the effects of these multiple parameters on final characteristics of the self-assemblies is a major challenge for the scientific community; however, despite this complexity, remarkable similarities and patterns are observed under certain conditions. For instance, amyloid aggregates originating from very different misfolding proteins possess a common structure typified by $\beta$-sheet-rich oligomers that assemble into long fibers organized according to a cross- $\beta$ structure of paired $\beta$-strands running perpendicular to the long axis. [2, 10]

Interaction of cell membranes with $\beta$-sheet nanofibers is a topic research field due to the high potential of peptide-drug amphiphiles for intracell delivery and appearance of these structures in a variety of biological processes such as cell adhesion, signaling and cytotoxicity.[11-18] Newcomb et al.[11] investigated cytotoxicity onto surfaces coated with nanofibers obtained from two kinds of surfactant-like peptides; namely, $\mathrm{C}_{16} \mathrm{H}_{31} \mathrm{O}-\mathrm{A}_{3} \mathrm{G}_{3} \mathrm{~K}_{3}$ and $\mathrm{C}_{16} \mathrm{H}_{31} \mathrm{O}-\mathrm{V}_{3} \mathrm{~A}_{3} \mathrm{~K}_{3}$ peptide amphiphiles (PAs). These PAs are characterized by cationic head groups (lysines) separated from alkyl tails by amino acid spacers able to drive the formation of $\beta$-sheet in the resulting nanofibers. Interestingly, they found that species containing valines as spacers form stable $\beta$-sheet-rich fibers, which are well-tolerated by cells. On the other hand, $\mathrm{C}_{16} \mathrm{H}_{31} \mathrm{O}-\mathrm{A}_{3} \mathrm{G}_{3} \mathrm{~K}_{3}$ assemblies do not show $\beta$-sheet features and instead exhibit higher cytotoxicity levels. The reasons for this are related to higher intermolecular cohesion observed in $\beta$-sheets, which hinders rapid incorporation of peptide moieties from fibers into cell membranes, preventing disruption. When they removed one lysine residue from the valine-free PA, cytotoxicity was found to significantly decrease. This behavior, with decreasing cationic charge leading to lower cytotoxicity levels, is also consistent with other reports [19] which investigated cytoxicity in lipids and polymer scaffolds and highlights the role of charges in cytotoxicity. Recently, we have taken advantage of $\pi-\pi$ stacking 
interactions and directionality provided by aromatic rings in phenylalanine side-chains and demonstrated the fibrillization behaviour of a sequence composed only of alternating arginine and phenylalanine residues, $[20]$ in the octamer $[R F]_{4}$. This sequence has been shown to comprise all main features of much more complex amyloid peptides, including their cross- $\beta$ organization. It is notable that this feature has been unambiguously determined for a cationic sequence, abundant in arginine, which is not typical of native amyloidogenic sequences. $L$-arginine is an amino acid widely found in cell-penetrating peptides which plays a central role in several biological processes.[21] Moreover, arginine-rich domains are often found in protein interaction hotspots[22] and appear at interfaces of liquid-liquid phase separation.[23] Thus, arginine-rich oligopeptides have particular behavior regarding interactions with other biomolecules, including cell membranes, and a proper understanding of structure-toxicity relationships in these species is well worth the effort. The current work is a step forward in this direction.

Herein, we investigate in detail both the structure and toxicity of alternating arginine/phenylalanine fragments with general form $[R F]_{n}(n=1-5)$. The chemical structures of the peptides are shown in the Supporting Information. These highly simplified sequences, containing only two L-amino acids in their composition, provide suitable models for exploring both structural and toxicity features of arginine-based oligopeptides. The structure of these peptides is unveiled in detail, from the nanoscale down to the level of molecular packing, and their cytotoxicity toward C6 rat glioma and RAW264.7 macrophage cell models is investigated. We find a rich polymorphism with a close relationship between structure and length of the peptide chain. Critical aggregation concentrations detected through pyrene fluorescence assays exhibit a general trend to decrease upon increase in the number of $[R F]$ repeats along the peptide backbone, possibly a consequence of diminution of charge density as the sequences become longer. The formation of irregular, oligomer-like, aggregates is observed even for the minimal $[R F]$ dimeric species; however, fibrillization requires at least four phenylalanine groups in the sequence. Interestingly, whereas octameric sequences form cross- $\beta$ structures with intertwined fibrils, the decamer $[\mathrm{RF}]_{5}$ self-assembles into paired $\beta$-strands within single pleated $\beta$-sheets which twist into thicker helical fibrils. Toxicity assays show that IC50 values are also dependent on peptide length, with longer sequences exhibiting higher inhibitory rates. The viability profiles are quite similar between different cell lines, suggesting that cell death is caused by a nonspecific mechanism. 


\section{MATERIALS AND METHODS}

Sample preparation: Alternating $\mathrm{RF}$ peptides $(\mathrm{R}=\operatorname{arginine}, \mathrm{F}=$ phenylalanine $)$ were customsynthesized by Peptide Protein Research Ltd. (Fareham, UK) and used as received. Four sequences were purchased from PPR Ltd: $[R F]_{1},[R F]_{2},[R F]_{3}$ and $[R F]_{5}$. All peptides used trifluoroacetic acid (TFA) as a counterion and the purity of purchased peptides was determined by the manufacturer through HPLC and electrospray-mass spectroscopy immediately after synthesis, revealing the following purity levels: $[\mathrm{RF}]_{1}$ : purity $=97.6 \%, \mathrm{M}_{\mathrm{w}}=322.2 \mathrm{~g} / \mathrm{mol}$ (calculated: $321.4 \mathrm{~g} / \mathrm{mol}$ ); $[\mathrm{RF}]_{2}:$ purity $=98.7 \%, \mathrm{M}_{\mathrm{w}}=625.5 \mathrm{~g} / \mathrm{mol}$ (calculated: $624.7 \mathrm{~g} / \mathrm{mol}$ ); $[\mathrm{RF}]_{3}$ : purity $=98.6 \%, \mathrm{M}_{\mathrm{w}}=927.7 \mathrm{~g} / \mathrm{mol}$ (calculated: $928.1 \mathrm{~g} / \mathrm{mol}$ ); and $[\mathrm{RF}]_{5}$ : purity $=95.1 \%, \mathrm{M}_{\mathrm{w}}=1535.2 \mathrm{~g} / \mathrm{mol}$ (calculated: $1534.8 \mathrm{~g} / \mathrm{mol}$ ). $[\mathrm{RF}]_{4}$ peptides were synthesized in our lab using standard solid-phase methods similar to described elsewhere [20, 24]; however, herein, acetylation steps were not performed. This sequence was characterized at our lab, showing purity $=96.4$ $\%$ and $\mathrm{Mw}=1231.6 \mathrm{~g} / \mathrm{mol}$ (calculated: $1231.5 \mathrm{~g} / \mathrm{mol}$ ). Structural and cytotoxicity assays were carried out within 6 months after receiving (or synthesizing) the sequences. Additional characterization was made on the same peptide batches after $\sim 24$ months (dry powder storage at $-20^{\circ} \mathrm{C}$ ) to assess stability and investigate elution times of all peptides under the same HPLC conditions. In despite some degree of degradation was noticed after this time, the batches kept purities $>90 \%$ for all $[R F]_{n}$ sequences and retention times were found to progressively increase upon length of $[R F]_{n}$ oligopeptide (see Fig. S4). HPLC and mass-spectroscopy data from both "fresh" and "aged" batches may be found in the SI file. Samples used in physico-chemical assays were prepared by dissolving the appropriate quantity of peptide into milli-Q water (or $\mathrm{D}_{2} \mathrm{O}$ for SANS and FTIR assays) at the desired final concentration. To ensure the formation of self-assemblies, samples were left to rest for at least 24 hours prior to further characterization. In the case of fluorescence assays, solutions were kept at room temperature for 1 day prior to analysis. Prior to SAXS, SANS and cryo-TEM experiments, samples were kept in the fridge at 4 ${ }^{\circ} \mathrm{C}$ for a period of $\sim 1$ week. For fiber XRD, aged solutions ( 4 weeks) were used for preparing the stalks. Fluorescence assays: A Carian Varian Ellipse spectrometer was used to obtain fluorescence data. Formulations containing peptides at concentrations ranging from $\sim 1 \mu \mathrm{M}$ to $\sim 30 \mathrm{mM}$ were prepared using a $5 \mu \mathrm{M}$ pyrene solution and the corresponding emission spectra were recorded upon illumination with an excitation wavelength $\lambda_{\mathrm{exc}}=338 \mathrm{~nm}$. Samples were transferred into $10 \mathrm{~mm}$ width quartz cuvettes and emission spectra were recorded in the interval $350 \mathrm{~nm} \leq \lambda_{\mathrm{em}} \leq 500 \mathrm{~nm}$, using $1 \mathrm{~nm}$ steps. Slits were regulated to provide the best achievable signal-to-noise ratios and the resulting spectra were normalized 
by a peptide-free pyrene solution spectrum. Fourier-transform infrared and circular dichroism: Fourier-transform infrared (FTIR) spectroscopy was performed using a Nicolet Nexus spectrophotometer. Samples were prepared in $\mathrm{D}_{2} \mathrm{O}$, at $10 \mathrm{mg} / \mathrm{ml}$. This concentration was chosen such that all sequences were either above the critical aggregation concentration or the number of [RF] pairs in the medium was the same, $c a .30 \mathrm{mM}$.. Droplets of peptide solutions were loaded between $\mathrm{CaF}_{2}$ windows, with a path length of $12 \mu \mathrm{m}$, and spectra were measured at a resolution of $4 \mathrm{~cm}^{-1}$. Averages from 128 accumulations were background-subtracted and noise reduction was performed using FFT filters with smoothing windows of 6 data points. Circular dichroism (CD) spectra were collected on a Chirascan spectropolarimeter (Applied Photophysics, UK). Solutions prepared at the same concentrations mentioned above (into $\mathrm{D}_{2} \mathrm{O}$ ) were sandwiched between demountable Hellma cuvettes with a path length of $0.01 \mathrm{~mm}$. Data were acquired with wavelength steps of $1 \mathrm{~nm}, 1$ second per point, averaged over 4 accumulations and background subtracted. Small-angle Scattering: Small-angle neutron scattering (SANS) measurements were carried out on beamline LOQ at ISIS spallation source (Didcot, UK). Peptide solutions at $10 \mathrm{mg} / \mathrm{mL}$ were prepared using $\mathrm{D}_{2} \mathrm{O}$ as a solvent and loaded into banjo cells with pathlength $1 \mathrm{~mm}$. The sample-todetector distance was kept at $4 \mathrm{~m}$ and the sample was placed in a "white" neutron beam with cross-section of $12 \mathrm{~mm}$ and wavelengths in the range $2.2 \AA \leq \lambda \leq 10 \AA$. Detection was carried out with a ${ }^{3} \mathrm{He}-\mathrm{CF}_{4}$ area detector with an active surface of $640 \times 640 \mathrm{~mm}^{2}$. Data reduction was performed with the Mantid package. This configuration allowed access to a $q$-range interval of $0.2 \mathrm{~nm}^{-1} \leq q \leq 2.5 \mathrm{~nm}^{-1}$, corresponding to direct-space lengths of $2.5 \mathrm{~nm} \leq d \leq 31 \mathrm{~nm}$. Small-angle X-ray scattering (SAXS) data were collected on either I911-4 at MaxLab II (Lund, Sweden) or SAXS1 beamline at LNLS (Campinas, Brazil). On I911-4, a volume of about $60 \mu \mathrm{l}$ of peptide solution was loaded into a $1 \mathrm{~mm}$ quartz capillary and oscillated forward and backward to prevent radiation damage. X-rays with $\lambda=0.91 \AA$ were used to illuminate the samples, placed at a distance of $915 \mathrm{~mm}$ from the detector. Acquisition was made with a Pilatus $1 \mathrm{M}$ detector and 4 frames, $30 \mathrm{~s}$ each, were averaged and background-subtracted. On SAXS1, about $300 \mu \mathrm{l}$ of sample were loaded into a $1 \mathrm{~mm}$ cell in between two mica windows. Ten frames, of $30 \mathrm{~s}$ each, were grabbed and solutions were kept static during data acquisition; however, no radiation damage was observed upon comparison between different frames. The X-ray wavelength was $\lambda=1.54 \AA$ and the sample-to-detector distance was kept at $1000 \mathrm{~m}$. Data were recorded in the interval $0.12 \mathrm{~nm}^{-1} \leq q \leq 4.5$ $\mathrm{nm}^{-1}$, providing information across the direct-space range $1.5 \mathrm{~nm} \leq d \leq 52 \mathrm{~nm}$. A Pilatus $1 \mathrm{M}$ detector was 
for used to record 2D scattering patterns. Fit2D was used for data reduction and radial averaging. Model fitting was carried out for both SANS or SAXS data using the SASFit program [25]. Cryo-TEM Imaging: In-situ cryogenic transmission electron microscopy (cryo-TEM) assays were performed on vitrified specimens obtained from $10 \mathrm{mg} / \mathrm{ml}$ peptide solutions. The microscope used for imaging the samples was a JEOL JEM-3200FSC using an acceleration voltage of $300 \mathrm{kV}$ and operating in bright-field mode with a slit width of $20 \mathrm{eV}$. Images were recorded with a Gatan Ultrascan $4000 \mathrm{CCD}$ camera. Grids were prepared by casting droplets containing about $3 \mu \mathrm{l}$ of peptide solutions, blotted once for $1 \mathrm{~s}$ and then vitrified into a FEI Vitrobot device using a 1:1 mixture of liquid ethane and propane at $-180{ }^{\circ} \mathrm{C}$. Prior to imaging, copper grids were kept in liquid nitrogen before being transferred into the microscope. Fiber $\mathbf{X}$ ray diffraction (XRD): Oriented stalks were prepared by suspending droplets from $10 \mathrm{mg} / \mathrm{ml}$ peptide solutions between wax-coated capillaries. The capillaries with droplets were accommodated within covered Petri dishes and the set up was sealed with laboratory film. To assist drying, a few silica-gel granules were enclosed together with the capillaries. Samples were left to dry in the fridge at $4{ }^{\circ} \mathrm{C}$ for a period of about 3 days. This procedure led to the formation of dried oriented stalks on the ends of the capillaries. Stalks were vertically positioned onto a RAXIS IV++X-ray diffractometer (Rigaku) equipped with a rotating anode generator and data were collected using a Saturn 992 CCD camera. Sample-todetector distances ranged from 40 to $50 \mathrm{~mm}$. Data reduction was carried out using Fit2D and unit-cell optimization was performed using the CLEARER software.[26] Cytotoxicity assays: Rat glioma (C6, ATCC $®$ CCL-107 ${ }^{\mathrm{TM}}$ ) and macrophage (RAW264.7, ATCC $®$ TIB-71 ${ }^{\mathrm{TM}}$ ) cell lines were cultivated in order to investigate the in vitro cytotoxic profile of $[R F]_{1-5}$. C6 cells were cultivated in DMEM and RAW264.7 in RPMI1640 which were supplemented with 10\% fetal bovine serum (FBS), 2 mM of Lglutamine and $0.5 \%$ of penicillin/streptomycin. The pHs of culture media were adjusted to 7.4 and 7.2 , respectively, for DMEM and RPMI1640. The cells were plated in 96-well plates at 4 x $10^{4}$ cells/well and were subjected to treatment with the peptide solutions after $24 \mathrm{~h}$. Peptide concentrations varied from $31.25 \mu \mathrm{g} / \mathrm{mL}-4 \mathrm{mg} / \mathrm{mL}$ and were incubated for $12 \mathrm{~h}$ with each cell line. The cell viability was assessed using the 3-(4,5-dimethylthiazol-2-yl)-2,5-diphenyltetrazolium bromide (MTT) assay. Data analysis and statistical treatment: Data were analyzed using GraphPad Prism 7.0 and Microsoft Office Excel 2016. Statistical tests comprised Student's unpaired $t$ tests, in which statistically significant comparisons were availed to the $5 \%$ level. Data are plotted as mean \pm standard error of mean (s.e.m.). 


\section{RESULTS AND DISCUSSION}

\subsection{Fluorescence studies}

The first step towards a detailed description of the self-assembly of alternating $[R F]_{n}(n=1$ to 5) sequences was the determination of critical aggregation concentrations (CACs) necessary to form peptide nanostructures. These studies were based on fluorescence assays using pyrene, a non-polar chromophore highly sensitive to local hydrophobicity.[27] Thus, by assessing its fluorescence as a function of peptide concentration in solution, it has been possible to obtain information on the presence of aggregates containing sequestered hydrophobic moieties.[28]

Emission spectra obtained from these assays (see SI file, Fig. S1) reveal intense fluorescence peaks at ca. $373 \mathrm{~nm}, 383 \mathrm{~nm}$ and $394 \mathrm{~nm}$, which are associated, respectively, to the $\mathrm{I}_{1}, \mathrm{I}_{3}$ and $\mathrm{I}_{5}$ vibronic bands of the pyrene chromophore.[27, 29] A typical strategy for estimating the CAC from pyrene fluorescence series consists in plotting the intensity ratio of the first and third vibrational bands, $\mathrm{I}_{1} / \mathrm{I}_{3}$, as a function of peptide concentration and then identifying changeovers.[30] Plots of $\mathrm{I}_{1} / \mathrm{I}_{3}$ versus $\log$ [peptide concentration], shown in Figure 1, exhibit Z-shaped profiles with emission ratios characterized by a smooth decrease upon increase of $[R F]_{n}$ concentration. The profiles were fitted to sigmoidal functions (red lines in Figure 1) using the Boltzmann equation:

$$
y=\frac{A_{1}-A_{2}}{1+\exp \left(\frac{x-x_{0}}{\Delta x}\right)}+A_{2}
$$

In Equation 1, $\mathrm{A}_{1}$ and $\mathrm{A}_{2}$ account for the upper and lower plateaus of the sigmoidal function, respectively. The slope of the curve, $\Delta x$, indicates how abrupt the transition between regimes is. The CAC is derived from the inversion centre of the curve, given by the adjusting parameter $x_{0}$. First derivatives were also calculated and the corresponding minima coincided with inflexions in the curves, accurately matching the inversion points. Critical concentrations obtained from the fits were determined to be $18.2 \pm$ 8.0, $0.04 \pm 0.01,2.3 \pm 1.3,0.3 \pm 0.1$ and $0.020 \pm 0.005 \mathrm{mM}$, respectively, for $[R F],[R F]_{2},[R F]_{3},[R F]_{4}$ and $[R F]_{5}$. Therefore, further analyses on structural aspects of $[R F]_{n}$ aggregates employed concentrations above these critical points. 
Although peptide self-assembly is known to be complex, with different types of aggregates and critical concentrations appearing along the aggregation pathway, some interesting features can be deduced from our CAC measurements. First, we should consider that pyrene $\mathrm{I}_{1} / \mathrm{I}_{3}$ ratio is highly sensitive to local polarity; thus, the CACs obtained are likely related to the formation of small hydrophobic clusters in solutions, regardless of the level of organization of the assemblies. Secondly, for longer sequences (i.e., $[R F]_{3},[R F]_{4}$ and $[R F]_{5}$ ), one observes that CACs decrease about one order of magnitude per additional $[\mathrm{RF}]$ repeat along the sequence. This behavior suggests that the length of the chains plays an important role for aggregation and charge density might well be a major contributor in the self-assembly process. In fact, since the number of $\mathrm{N}$ - and $\mathrm{C}$-termini remains unchanged for different constructs, by increasing the number of repeats along the backbone, charge density presumably diminishes as peptides become longer. Therefore, electrostatic repulsions between charged chains should be suppressed and aggregation of longer peptides facilitated. In addition, enrichment in guanidinium moieties also improves the H-bond donation/acceptance capabilities of the peptides[31,32] and increasing the number of aromatic groups likely enhances the formation of $\pi-\pi$ and cation- $\pi$ interactions. On the other hand, data from shorter sequences, $[R F]$ and $[R F]_{2}$, are less straightforward to interpret. In this case, critical concentrations differed by several orders of magnitude with $[\mathrm{RF}]_{2}$ exhibiting a CAC $\sim 40 \mu \mathrm{M}$, comparable to $[\mathrm{RF}]_{5}$. We hypothesize that the low molecular weight of these peptides, similar to that of pyrene, affects the fluorescence behavior due to interactions between the probe and monomeric species.

\subsection{Structural analyses}

The secondary structure of $[\mathrm{RF}]_{1-5}$ constructs was assessed through Fourier-transform infrared and circular dichroism (FTIR and CD). In Figure 2A, FTIR spectra from solutions prepared in $\mathrm{D}_{2} \mathrm{O}$ indicate that vibrational spectra are influenced by the length of the peptides. Particularly, one observes that complexity of amide I region increases upon addition of [RF] repeats, with a larger number of vibrational modes appearing for longer sequences. In spectra from samples containing the shortest peptide $[R F]$, the landscape is dominated by a broad maximum placed around $\sim 1590 \mathrm{~cm}^{-1}$, which is tentatively assigned to symmetric stretching vibrations in guanidinium groups in arginine side-chains.[33] Data from sequences with two or more $[R F]$ repeats show a sharp peak at $\sim 1674 \mathrm{~cm}^{-1}$, consistent with either 
vibrations arising from TFA counter-ions[20] and/or the presence of $\beta$-sheets in self-ordered structures.[34, 35] In fact, $\mathrm{pH}$ measurements performed in aqueous solutions (see Fig. S2-A, SI file) containing peptides dissolved at concentrations similar to those used in FTIR assays indicate acidity (pH 4-5), which likely arises from TFA in the medium. Bands widely ascribed to $\beta$-sheets are found at 1611 , 1622, 1629 and $1641 \mathrm{~cm}^{-1}$, suggesting that this is the dominant conformation in the constructs. The presence of $\beta$-turns is inferred from noticeable shoulders at 1659 and $1691 \mathrm{~cm}^{-1}$, particularly in samples prepared with $[\mathrm{RF}]_{4}$ and $[\mathrm{RF}]_{5}$. In the case of the octamer, a small content of unordered conformations is also indicated by a shallow band at $1650 \mathrm{~cm}^{-1}$.

$\mathrm{CD}$ data displayed in Figure 2B also highlights correlations between secondary structure and peptide length. To compare spectra from peptides with different sizes, CD units were converted into mean residue molar ellipticity, $[\theta]_{\mathrm{MRW}}$. The composition of $[\mathrm{RF}]_{\mathrm{n}}$ peptides should be taken into account for interpreting the data since their optical activity can be strongly biased toward transitions arising from phenylalanine and arginine side-chains. The extensive presence of phenylalanine residues leads to mixed bands arising from either peptide backbone or aromatic rings,[36] whereas charged amine groups in guanidinium side-chains potentially produces red shifts in the spectra.[36, 37] Despite these difficulties, it was possible to identify several features consistent with the formation of $\beta$-sheet structures suggested by FTIR above. In the case of the $[R F]$ solution, the CD spectrum is characterized by a large positive band centered at $213 \mathrm{~nm}$, which has been assigned to transitions in the phenylalanine side-chain.[20, 38] Similar behaviors were found in spectra from $[R F]_{2}$ and $[R F]_{3}$ peptides, excepting that in these samples positive peaks were red shifted to $\sim 218 \mathrm{~nm}$. No addition features were found in these samples and further assignment could not be made on the basis of CD information. In the case of $[R F]_{4}$ and $[R F]_{5}$, however, the picture is different and CD spectra are characterized by a bisignate Cotton effect attesting the presence of chiral self-assemblies. Pairs of positive/negative peaks appear at 220/232 nm and 209/226 nm, respectively. Although showing strong red shifts (ca. 15 and $10 \mathrm{~nm}$, for $[\mathrm{RF}]_{4}$ and $[\mathrm{RF}]_{5}$ ), these peaks give the spectra a $\beta$-sheet appearance, indicating the presence of this conformation in assemblies from the longer sequences. These data suggest that $\beta$-sheet content is enhanced as the number of $[R F]$ units increases in the sequences, consistent with findings arising from FTIR.

To probe nanoscopic features in our model $[R F]_{1-5}$ peptides, a combination of small-angle neutron and X-ray scattering (SANS and SAXS) was used to investigate the organization of aggregates in 
solution. Solutions were prepared at concentrations at least twice the CAC values obtained from fluorescence assays in order to ensure the formation of aggregate structures. In Fig. 3A, we show SANS curves from samples containing peptides dissolved in $\mathrm{D}_{2} \mathrm{O}$.[39] The curves exhibit distinct profiles, indicating that different shapes appear in solution depending on the length of peptides. SANS data reveal distinguishable information for mixtures containing the dimer $[R F]$, the octamer $[R F]_{4}$ and the decamer $[R F]_{5}$. Curves from samples prepared with $[R F]_{2}$ and $[R F]_{3}$ show poor signal-to-noise ratios, presumably indicating that these samples are mostly populated by low-molecular weight species below the detection limit of the technique.

We started quantitative data analysis by assessing the low- $q$ region of the curves to identify scaling exponents and unveil information on the general shapes of particles in solution.[40] In the case of samples containing the $[\mathrm{RF}]$ motif, it was found that the small-angle region is characterized by an intensity decay scaling with $\sim \mathrm{q}^{-2.8}$, consistent with clustered networks. [41, 42] To provide more detailed information on radius of gyration $\left(R_{g}\right)$ and dimensionality $(d)$ of these structures, we carried out full-range fitting using a fractal model combined with an exponential cutoff function, $[43,44]$ available within the SASFit software library [25]. An additive constant was introduced in the model to properly describe background scattering. The obtained fitting parameters were $R_{g}=45.9 \mathrm{~nm}$ and $d=2.86$, consistent with dimensions of nanostructures in cryo-TEM images. In the case of curves from samples containing $[\mathrm{RF}]_{4}$ and $[\mathrm{RF}]_{5}$, the low- $q$ region was found to possess a smooth decay scaling with $\sim \mathrm{q}^{-1.2}$, which corresponds to the presence of cylindrical structures in solution.[39] Full-range model fitting was performed using a Porod cylinder form factor plus a background constant. The polydispersity in the thickness of cylinders was described using a Gaussian radius distribution $[20,45]$. Data from $[R F]_{4}$ samples were described by long cylinders with average radius $R=4.1 \pm 0.6 \mathrm{~nm}$. Data from a $[\mathrm{RF}]_{5}$ solution was fitted considering much thinner and monodisperse cylinders with radius $R=2.6 \pm 0.1 \mathrm{~nm}$.

High-resolution SAXS provided greater insights into the structure of polymorphs. Samples were prepared by dissolving the peptides in $\mathrm{H}_{2} \mathrm{O}$ at the same concentrations used for SANS (and CD and FTIR) measurements. Scattering curves from these experiments are displayed in Fig. 3B, revealing that the highflux provided by synchrotron radiation allows for information on nanostructures to be obtained from SAXS. In particular, the presence of self-assemblies in $[R F]_{2}$ and $[R F]_{3}$ samples is revealed and, since data extended to higher $\mathrm{q}$ than in the SANS measurements, information on smaller species could also be 
accessed. Similar to SANS, the shape of the scattering profiles exhibits a dependence on the size of the peptides, confirming that different morphologies populate the samples.

Data from the $[R F]$ solution show different levels of organization across the $q$-range investigated, one concerning large-scale features at low- $q$ and another related to local structure of the assemblies at high- $q$ (see bottom curve in Fig. 3B). The low- $q$ region (i.e., $\mathrm{q}<\sim 0.5 \mathrm{~nm}^{-1}$, carrying information on sizes greater than $\sim 10 \mathrm{~nm}$ ) falls off as $\sim q^{-3}$, consistent with clustered networks as revealed by SANS. On the other hand, the high- $q$ range exhibits intensity scaling as $\sim q^{-0.5}$, which suggests that the local structure of aggregates comprises compact particles [42]. Quantitative information from these multi hierarchical architectures was obtained by data fitting using a combination of form factors comprising the mass fractal model used above to describe large-scale features and the generalized Gaussian coil chain model [46] to account for local organization (see SI file). This model provides both the radius of gyration $R_{g}$ of coiled chains and the Flory excluded volume parameter $v$, which is related to peptide/solvent interactions $[39,46]$. For large-scale structure, the fitting procedure led to the parameters $R_{g}=79.7 \mathrm{~nm}$ and $d=2.9$, revealing larger aggregates than those found in SANS measurements. The local structure was characterized by a radius of gyration $R_{g}=0.5 \mathrm{~nm}$ and a Flory exponent $v=0.27$, consistent with collapsed coiled chains. $[39,47]$ These findings indicate that $[R F]$ self-assemblies are built up from globular subunits, which form fractal aggregates with dimensions of a few hundreds of nanometers.

SAXS intensity profiles from $[\mathrm{RF}]_{2}$ solutions revealed details on low-molecular weight species. The intermediate $q$-range is characterized by a near-flat scattering pattern followed by a steep descent at high $q$, which is consistent with small fractal aggregates [48]. The low- $q$ region, related to larger structures, is very noisy and does not allow for reliable information to be obtained. These findings suggest that self-assemblies formed by this peptide are rather composed by small oligomers with a small population of large aggregates. To provide measurements on structural parameters, we performed fullrange fitting using the generalized Gaussian coil model already employed to describe data from the dimeric peptide. The fitting parameters related to these curves were $R_{g}=0.6 \mathrm{~nm}$ and $v=0.3$, consistent with unimers in solution.

Scattering profiles from $[\mathrm{RF}]_{3}$ samples provided richer information on aggregates in solution. The intermediate-to-high $q$-range of the data (Fig. 3B) was found to be quite similar to those observed for 
$[\mathrm{RF}]_{2}$ assemblies, suggesting that the local structure comprises mainly unimers with collapsed coil features. To describe this region, model fitting has been performed in the same manner used above leading to structural parameters $R_{g}=0.6 \mathrm{~nm}$ and $v=0.3$. However, the data also indicated the presence of larger aggregates as attested by an upturn in intensity at low $q$. To fit this region carrying information on bigger structures, we used a fractal form factor which led to structural parameters of $R_{g}=39.8 \mathrm{~nm}$ and $d=$ 2.6, respectively, for the radius of gyration and dimensionality. These features are consistent with the presence of fractal aggregates composed of interconnected sub-units.

Data from samples prepared with $[\mathrm{RF}]_{4}$ and $[\mathrm{RF}]_{5}$ reveal higher signal-to-noise ratios, showing that these solutions contain a significant fraction of aggregates with sizes within the lengths probed by SAXS (see upper curves in Fig. 3B). In the case of the octamer $[\mathrm{RF}]_{4}$, the high $q$ range is characterized by the same steep descent behavior ascribed to small fractal-like aggregates. The low $q$ range is consistent with the presence of cylindrical structures as previously found,[20] and to provide quantitative description of the data we have used a combination of long Porod cylinder and Gaussian coil form factors. A Gaussian radius distribution was introduced in the model to account for polydispersity of fiber thicknesses. The fitting parameters arising from this procedure revealed a population of highly polydisperse cylinders with radius $R=5.1 \pm 2.5 \mathrm{~nm}$, in coexistence with small coiled structures with $R_{g}=$ $0.9 \mathrm{~nm}$ (probably unimers). It should be noted that the thickness of cylinders, with diameter averaging $10 \mathrm{~nm}$, is consistent with typical dimensions found in amyloid fibers and the coexistence with oligomeric species gives to $[\mathrm{RF}]_{4}$ aggregates strong characteristics of amyloidogenic peptides $[10,20,49]$.

Among solutions containing $[\mathrm{RF}]_{1-5}$ peptides, those prepared with the decamer $[\mathrm{RF}]_{5}$ exhibited the most characteristic SAXS profiles. The outline of this curve displays several features which are noticed in none of the other samples. For instance, the remarkable high $q$ descent is much shorter than in previous samples and a clear maximum, characteristic of monodisperse particles [39], is now visible at $\mathrm{q}$ $\sim 2.5 \mathrm{~nm}^{-1}$. In addition, high-resolution SAXS allows the resolution of some bumps along the low-tointermediate $q$-values, suggesting the presence of core-shell structures $[45,50,51]$. Data at small-angle region fall off with $\sim \mathrm{q}^{-1}$, indicating rigid 1-D morphology. To extract quantitative information, we fitted SAXS profiles from $[\mathrm{RF}]_{5}$ solutions with a combination of fractal and core-shell cylinder form factors $[43,52]$. Interestingly, no polydispersity distribution was needed to fit these data, confirming that $[\mathrm{RF}]_{5}$ forms highly monodisperse polymorphs. For the cylinder-shell component, the core radius was found to be $R=1.9 \mathrm{~nm}$, whereas the shell thickness was determined to be $\Delta R=1.7 \mathrm{~nm}$. These values combined 
reveal self-assembly into hollow cylinders with internal diameter equal to $3.8 \mathrm{~nm}$ and overall diameter 7.2 nm. These values are compatible with SANS experiments, where fits carried out with solid cylinder modeling indicated an average diameter of $5.2 \mathrm{~nm}$. It should be noted that the differences between SANS and SAXS measurements are associated either with the scattering contrasts provided by each technique or the employment of distinct fitting models. Structural parameters arising from both neutrons and X-rays scattering are summarized in Table S1 (SI).

The morphology of $[R F]_{1-5}$ self-assemblies was imaged using cryo-TEM. Cryo-TEM provides high-resolution visualization from vitrified specimens preserving the main features of the liquid-phase ordering of biomolecular aggregates. [53] In Figure 4, we show representative images from aqueous solutions containing $[R F]_{n}$ peptides. One clearly sees the formation of nanosized aggregates with forms and dimensions depending on the length of the peptide. In the case of samples containing the dimeric unit [RF], shown in Fig. 3, the solution is populated by a large number of globular structures. The presence of these small aggregates is a feature observed throughout the $[R F]_{1-5}$ series investigated in this study and it corroborates the propensity of these peptide species to form oligomeric polymorphs.[20] Moreover, it is possible to identify larger aggregates in which these globules appear self-associated and form superstructures resembling ramified beads-on-string arrays. These arrangements vary in either shape or dimension and they are typically composed of $5-20$ subunits with overall size $\sim 50 \mathrm{~nm}$. In $[\mathrm{RF}]_{2}$ solutions (Fig. 4) the smaller round objects are also present; however, larger-scale structures formed from their association are much scarcer. Characteristic dimensions of the superstructures produced from $[\mathrm{RF}]_{2}$ are about twice the size of aggregates observed in $[R F]$ samples. In samples prepared with $[R F]_{3}$, the morphology of the resulting self-assemblies keeps the general features described above and $\sim 10 \mathrm{~nm}$ beads appear coalesced into larger interconnected architectures (Fig. 4). The characteristic ramifications found in the previous peptides are maintained and typical dimensions are around $70 \mathrm{~nm}$.

When longer $[\mathrm{RF}]_{4}$ or $[\mathrm{RF}]_{5}$ (Fig. 4, bottom row) peptide solutions are imaged, the morphology changes dramatically. Specifically, long fibers with diameters of just a few nanometers are observed. In solutions containing the octamer $[\mathrm{RF}]_{4}$, it is possible to observe coexistence of smaller round particles and fibers with diameter $\sim 8 \mathrm{~nm}$, consistent with previous results revealed by SAXS. In the case of $[R F]_{5}$, the appearance of fibers is even more evident (Fig.4E). In fact, it can be observed that the sample exhibits a mixture of globules with diameters averaging $\sim 20 \mathrm{~nm}$ and very long fibers with cross-sections only $\sim 5$ 
$\mathrm{nm}$. In contrast to shorter sequences, the formation of irregular branched aggregates is not observed for longer sequences $(n>3)$.

$\mathrm{X}$-ray diffraction $(\mathrm{XRD})$ was used to probe the sub-nanometer scale structure of the $[\mathrm{RF}]_{1-5}$ aggregates. Two-dimensional patterns from dried stalks are shown in Figure 5A, revealing that the close relationship between structure and peptide length is kept at the molecular level. As a rule, the patterns are composed of concentric rings which increase in number as the size of the peptide grows. In fact, patterns obtained from $[R F]$ and $[R F]_{2}$ solutions show a limited number of Bragg reflections and are dominated by large and diffuse peaks whereas data from samples with longer sequences exhibits up to ten well-defined peaks indicating that peptide chains in these self-assemblies are organized into highly-packed structures. Also, patterns obtained from $[\mathrm{RF}]_{4}$ and $[\mathrm{RF}]_{5}$ preparations show partially-oriented reflections (see black arrows in Fig. 5) which are consistent with vertically-aligned fibers.

To quantitatively analyze the 2D patterns, we performed radial averaging to obtain the $q$ dependence of the diffraction intensities (Figure 5B). The peak positions and the corresponding real-space $D$-spacing are listed in Table 1. Unit cell optimization was carried out using the software CLEARER [26] and indexations are shown together with experimental $D$-spacings in Table 1 . Interestingly, despite strong differences in lattice parameters for peptides with different lengths, all diffractograms could be indexed according to orthorhombic P $2{ }_{1} 2_{1} 2_{1}$ unit cells in agreement with structural features found in other amyloidforming peptides $[10,20,45,54-56]$. $[R F]_{3-5}$ show a series of peaks corresponding to layer structures and the $\mathrm{D}$ spacing for each is around $3 \mathrm{~nm}$. In addition, one observes that a strong and sharp peak appears at $D$ $\sim 0.48 \mathrm{~nm}$ in patterns from sequences containing three or more [RF] repeats, which is assigned to the separation between hydrogen bonded $\beta$-strands [10, 57-59]. Unit cell indexation (see Table 1) shows that this meridional reflection is associated to the [002] reflection and thus corresponds to a second order peak. [10]

Table 1. Indexation of fiber XRD data shown in Fig. 5. Experimental data (Exp.) and calculated $D$ spacings (Calc.) are shown alongside with the corresponding Miller indices (hkl). All samples were indexed according to orthorhombic unit cells with space group $\mathrm{P} 2{ }_{1} 2_{1} 2_{1}$ and lattice parameters $a, b$ and $c$ (bottom row). 
shell. This picture is consistent with twisted $\beta$-sheet fibrils running helicoidally along the long axis. This configuration leads to a denser peptide core surrounded by a shell where the electron density is lower compared to that observed in the center. A graphical sketch of this proposed structure is found in SI Figure S3.

From the structural data presented above, one observes that the longer peptides investigated in this work, namely $[\mathrm{RF}]_{4}$ and $[\mathrm{RF}]_{5}$, exhibit features of amyloid peptides.[49, 55] In particular, these sequences are fibril-forming and show strong characteristics of cross $-\beta$ organization. The presence of aromatic residues is a remarkable characteristic of short amyloid-forming peptides.[64] It has been proposed that $\pi$-stacking interactions between phenyl rings provide directionality needed for selfassembly into 1-D scaffolds such as nanotubes and fibers and, thus, stacking could be at the origin of the fibers observed here.[65] This statement is supported by the growth of crystalline ordering observed upon increasing the number of phenylalanine residues in the sequences. Therefore, these extremely simplified peptides containing only arginine as a polar group, show clear fibrillogenic capabilities if a minimum number of aromatic residues are intercalated along the sequence to provide directionality during the selfassembly. This finding is particularly attractive considering the role of arginine moieties whose Y-shaped side-chain is thought to be involved in the adhesion of proteins to membranes and their fusogenicity and lysis.[66, 67] To analyze the toxicity effects of these model-peptides in biological medium we have undertaken cell assays.

\subsection{Cytotoxicity profiles in C6 and RAW264.7 cell lines}

Several human diseases are associated to peptide self-assembly, including disorders related to the formation of amyloid fibrils. Consequently, these aggregates or their oligomeric forms have been considered toxic.[68] However, recent studies have shown that some proteins can form amyloid-like fibrils without association with diseases.[69] In fact, the discovery of beneficial functions of some amyloids indicates that these structures may have normal physiological functions.[70] Amyloid formation varies among different cell types.[71] For example, endocytosis and phagocytosis competent cell-like macrophages and microglia form more $\mathrm{A} \beta$ plaques than neuroblastoma cells.[71]

Based on these observations, and inspired by amyloid features exhibited by the above sequences, we chose the murine macrophage cell line RAW264.7 and rat glioma cell line C6 to test the cytotoxicity 
of $[R F]_{n}$. As cytotoxicity can be induced by the free or aggregated $[R F]_{n}$, MTT assays were performed at several $[R F]_{n}$ concentrations, which were higher and lower than the estimated CAC values for each $[R F]_{n}$ peptide. To characterize cytotoxicity, a $[R F]_{n}$ concentration required to eliminate $50 \%$ of cells (IC50) was determined for each $[R F]_{n}$ for each cell line by a non-linear fitting to a variable slope sigmoid equation (Table 2). Dose-response curves for each $[R F]_{n}$ in both cell lines showed similar behavior (Figure 6). In the same manner as for structural observables investigated above, a length dependence of the IC50 parameter was found for cytotoxicity with longer the peptides showing higher cytotoxicity rates. Since our peptides are supplied as TFA salts, we measured the $\mathrm{pH}$ of the culture media and found that their buffering capacity was not exhausted even when peptides appeared dissolved at concentrations much higher than the IC50 values reported in Table 2 (see Figs.S2 B and C, SI file). It is known that cationic peptides are electrostatically attracted to the anionic cell membrane mainly due to their charge, and the accumulation of these peptides can lead to membrane lysis.[72, 73] This mechanism, in principle, could explain the nonspecific cell death we observed, as the constructs possess at least one cationic residue of arginine $(\mathrm{R})$, resulting in the concentration-dependent response shown. In addition, statistically equal IC50 values between RAW264.7 and C6 cell lines suggest that the mechanism of cytotoxicity is not dependent on endocytosis/phagocytosis, but instead it seems rather to be a consequence of nonspecific interactions of $[R F]_{\mathrm{n}}$ peptides with cell membranes.

To examine if the origin of this effect is a mere consequence of positive charges arising from arginine content in the formulations, we computed concentrations of R residues associated with each IC50 value derived from cytotoxicity assays. This was calculated just by multiplying the IC50 quantities by the number of $\mathrm{R}$ amino acids in the corresponding sequences. From these simple calculations, we determined that arginine concentrations at IC50 points range from $c a .22 \mathrm{mM}$, for the [RF] dimer, down to only $c a .1$ $\mathrm{mM}$ in the case of the $[\mathrm{RF}]_{5}$ decamer. Thus, the content of cationic residues, alone, does not explain the toxicity of these peptides. We plotted IC50 as a function of the number of repeats along the peptide chain incubated with the cells (Figure 7). The characteristic IC50 parameter was found to follow a decaying behavior which was almost perfectly fitted with a simple exponential function $\left(R^{2}\right.$ adj. $\left.>0.98\right)$. The similar behavior of the two cell lines is also observed for this comparison and the presence of an asymptotic limit for IC50 upon increasing number of $[\mathrm{RF}]$ units suggests that charge increase does not improve toxicity indefinitely. In light of these findings, we propose that structural features play a major role for toxicity. Particularly, since IC50 concentrations were found to be comparable or higher than 
CACs, we hypothesized that formation of assemblies also play a role for cell death. In this hypothesis, the formation of aggregates adhered onto membrane surface leads to "hot spots" where local charge density is highly increased, facilitating disruption. This behavior, with increasing charges leading to higher cytotoxicity levels, is consistent with previous reports.[19] Our results can also be compared with those obtained by Newcomb et al.[11], who found $\beta$-sheet fibers to be less toxic than $\beta$-sheet-free assemblies. Since here we have found $\beta$-sheet features in assemblies from all constructs (excepting the [RF] dimer), it our results imply an effect of charge independent of secondary structure. In addition, since both cells and peptides coexist in the bulk of solution during the self-assembly process, cell membranes also interact with oligomers during the fibrillization process. The less tight packing of oligomer intermediates is likely to enable release of peptide monomers in the vicinities of membrane surface, also facilitating the interaction between membrane and charged peptides groups.

Table 2 - IC50 obtained for each $[\mathrm{RF}]_{\mathrm{n}}$ in $\mathrm{C6}$ and RAW264.7 cell lines.

\begin{tabular}{|c|c|c|c|}
\hline \multirow{2}{*}{ Peptide } & \multicolumn{2}{|c|}{ IC50 (mM) } & \multirow{2}{*}{ p value* } \\
\cline { 2 - 4 } & C6 & RAW264.7 & 0,880 \\
\hline$[\mathrm{RF}]$ & $23.43 \pm 8.60$ & $21.74 \pm 7.10$ & 0,296 \\
\hline$[\mathrm{RF}]_{2}$ & $12.97 \pm 2.55$ & $9.12 \pm 2.61$ & 0,285 \\
\hline$[\mathrm{RF}]_{3}$ & $5.25 \pm 1.01$ & $3.22 \pm 1.59$ & 0,432 \\
\hline$[\mathrm{RF}]_{4}$ & $0.730 \pm 0.146$ & $0.474 \pm 0.289$ & 0,054 \\
\hline$[\mathrm{RF}]_{5}$ & $0.228 \pm 0.037$ & $0.146 \pm 0.014$ & \\
\hline
\end{tabular}

*IC50 from each $[\mathrm{RF}]_{\mathrm{n}}$ was compared between two cell lines and analyzed by Student's unpaired $t$-test.

\section{CONCLUSIONS}

We present an extensive study of the self-assembly and structure of arginine/phenylalanine oligopeptides, with sequence lengths varying from dimers to decamers. A combination of spectroscopy methods, small-angle scattering, X-ray diffraction and in-situ cryo-EM was used to provide a detailed structural picture of peptide aggregates whereas cytotoxicity toward rat brain glioma C6 and murine macrophage RAW264.7 cell lines was examined through MTT assays. To our knowledge, this is the first systematic study of length dependence in arginine-rich peptides yielding simultaneous information on both supramolecular structure and cytotoxicity. 
Our findings led to the discovery of different levels of organization in the aggregates, the progressive degree of order increasing with the number of $[R F]$ pairs along peptide backbone. Such length dependence was also found for different observables, including critical aggregation concentrations, appearance of chiral assemblies and toxicity. Dramatic changes in both aggregation and structural behaviors are ascribed to a decrease of charge density and enhancement of H-bond, $\pi-\pi$ and cation- $\pi$ interactions upon enrichment of guanidinium and benzene groups in the peptides. Shorter sequences selfassemble into fractal-like aggregates (with significant content of unaggregated unimer) whereas clear fibrillogenic capabilities are identified for longer peptides. Octameric and decameric sequences exhibited well-ordered crystalline phases and, although appearance of $\beta$-sheet conformations is observed even in sequences as short as $[R F]_{2}$, the formation of fibrils required at least four $[R F]$ repeats. $[R F]_{4}$ possesses all the main features of typical $\mathrm{A} \beta$ amyloids, with cross- $\beta$ structures composed of paired pleated $\beta$-sheets running parallel to the long axis of the fibers. Interestingly, $[R F]_{5}$ peptides exhibit a slightly different selfassembly, with the formation of thinner structures, likely composed of single pleated $\beta$-sheets twisting into helical fibrils.

MTT assays revealed dose-dependent profiles with cell death rates exhibiting very similar behavior for both glioma and macrophage cell lines. This finding was interpreted as evidence for a nonspecific mechanism involved in toxicity and, since IC50 values were found to be comparable to or higher than CACs, we propose that structural organization of $[\mathrm{RF}]_{\mathrm{n}}$ peptides is an important process regarding toxicity. In fact, the formation of small aggregates should be a necessary step for activating phagocytic pathways in the macrophages and aggregation is likely a critical condition for toxicity possibly due to the strong increase of local charge density induced by self-assemblies rich in cationic groups when interacting with cell membranes.

\section{CONFLICT OF INTEREST}

The authors report no conflict of interest on the content presented in this article. 
This work was supported by the Sao Paulo Research Foundation (FAPESP) under grant $\mathrm{n}^{\circ}$ 2016/24409-3. E.L. acknowledges CAPES for a M.Sc. fellowship. S.W.H. and W.A.A. are supported by FAPESP under grants $n^{\circ}$ 2015/20216-8 and 15/24018-1. I.W.H. acknowledges EPSRC for the award of a Platform Grant (ref. EP/L020599/1) and a Wolfson Research Merit Award. B.M.S. is grateful to CAPES for a doctoral fellowship. Beamline staff at LOQ (Didcot, UK, proposal 1510029), MaxLab (Lund, Sweeden, proposal 20140431) and LNLS (Campinas, Brazil, 20150176) are kindly acknowledged for technical support during SANS and SAXS experiments. Dr. Jani Seitsonen (Aalto University) is kindly acknowledged for providing cryo-EM imaging from $[\mathrm{RF}]_{4}$ peptide. Prof. Adriana Karaoglanovic Carmona and Lucas Rodrigues de Mello (Biophysics Dept, UNIFESP) are kindly acknowledged for providing access and assistance during fluorescence experiments. Rogerio Lauria (lab technician at Biophysics Department/UNIFESP) is kindly acknowledged for performing HPLC analyzes on aged peptides.

\section{REFERENCES}

[1] G. Wei, Z. Su, N.P. Reynolds, P. Arosio, I.W. Hamley, E. Gazit, R. Mezzenga, Selfassembling peptide and protein amyloids: from structure to tailored function in nanotechnology, Chem. Soc. Rev., (2017).

[2] I.W. Hamley, The Amyloid Beta Peptide: A Chemist's Perspective. Role in Alzheimer's and Fibrillization, Chemical Reviews, 112 (2012) 5147-5192.

[3] C.M. Dobson, Principles of protein folding, misfolding and aggregation, Semin Cell Dev Biol, 15 (2004) 3-16.

[4] R.F. Silva, D.R. Araújo, E.R. Silva, R.A. Ando, W.A. Alves, I-Diphenylalanine Microtubes As a Potential Drug-Delivery System: Characterization, Release Kinetics, and Cytotoxicity, Langmuir, 29 (2013) 10205-10212.

[5] E.R. Silva, G. Cooney, I.W. Hamley, W.A. Alves, S. Lee, B.F. O'Connor, M. Reza, J. Ruokolainen, D. Walls, Structural behaviour and gene delivery in complexes formed between DNA and arginine-containing peptide amphiphiles, Soft Matter, 12 (2016) 9158-9169.

[6] R.C. Bianchi, E.R. da Silva, L.H. Dall'Antonia, F.F. Ferreira, W.A. Alves, A Nonenzymatic Biosensor Based on Gold Electrodes Modified with Peptide Self-Assemblies for Detecting Ammonia and Urea Oxidation, Langmuir, 30 (2014) 11464-11473.

[7] Y. Cui, S.N. Kim, R.R. Naik, M.C. McAlpine, Biomimetic Peptide Nanosensors, Accounts Chem. Res., 45 (2012) 696-704.

[8] J. de Pedro-Cuesta, P. Martinez-Martin, A. Rabano, E. Alcalde-Cabero, F.J.G. Lopez, J. Almazan-Isla, M. Ruiz-Tovar, M.J. Medrano, F. Avellanal, O. Calero, M. Calero, Drivers: A Biologically Contextualized, Cross-Inferential View of the Epidemiology of Neurodegenerative Disorders, J Alzheimers Dis, 51 (2016) 1003-1022. 
[9] R.H. Zha, S. Sur, S.I. Stupp, Self-assembly of Cytotoxic Peptide Amphiphiles into Supramolecular Membranes for Cancer Therapy, Advanced Healthcare Materials, 2 (2013) 126-133.

[10] L. Serpell, Amyloid structure, Essays Biochem, 56 (2014) 1-10.

[11] C.J. Newcomb, S. Sur, J.H. Ortony, O.-S. Lee, J.B. Matson, J. Boekhoven, J.M. Yu, G.C. Schatz, S.I. Stupp, Cell death versus cell survival instructed by supramolecular cohesion of nanostructures, Nature Communications, 5 (2014) 3321.

[12] C.J. Newcomb, S. Sur, S.S. Lee, J.M. Yu, Y. Zhou, M.L. Snead, S.I. Stupp, Supramolecular Nanofibers Enhance Growth Factor Signaling by Increasing Lipid Raft Mobility, Nano Letters, 16 (2016) 3042-3050.

[13] A.R. Cormier, X. Pang, M.I. Zimmerman, H.-X. Zhou, A.K. Paravastu, Molecular Structure of RADA16-I Designer Self-Assembling Peptide Nanofibers, ACS Nano, 7 (2013) 7562-7572.

[14] S. Ribeiro, E. Radvar, Y. Shi, J. Borges, R.P. Pirraco, I.B. Leonor, J.F. Mano, R.L. Reis, A. Mata, H.S. Azevedo, Nanostructured interfacial self-assembled peptide-polymer membranes for enhanced mineralization and cell adhesion, Nanoscale, 9 (2017) 13670-13682.

[15] M.I. Souza, T. Prieto, T. Rodrigues, F.F. Ferreira, F.B. Nascimento, A.O. Ribeiro, E.R. Silva, F. Giuntini, W.A. Alves, Conjugation with L,L-diphenylalanine Self-Assemblies Enhances In Vitro Antitumor Activity of Phthalocyanine Photosensitizer, Scientific Reports, 7 (2017) 13166.

[16] A. Hategan, M.A. Bianchet, J. Steiner, E. Karnaukhova, E. Masliah, A. Fields, M.H. Lee, A.M. Dickens, N. Haughey, E.K. Dimitriadis, A. Nath, HIV Tat protein and amyloid-beta peptide form multifibrillar structures that cause neurotoxicity, Nature Structural \& Molecular Biology, 24 (2017) 379-+.

[17] H. Choi, M.T. Jeena, L. Palanikumar, Y. Jeong, S. Park, E. Lee, J.-H. Ryu, The HAincorporated nanostructure of a peptide-drug amphiphile for targeted anticancer drug delivery, Chemical Communications, 52 (2016) 5637-5640.

[18] S. Eskandari, T. Guerin, I. Toth, R.J. Stephenson, Recent advances in self-assembled peptides: Implications for targeted drug delivery and vaccine engineering, Advanced Drug Delivery Reviews, 110-111 (2017) 169-187.

[19] H. Lv, S. Zhang, B. Wang, S. Cui, J. Yan, Toxicity of cationic lipids and cationic polymers in gene delivery, Journal of Controlled Release, 114 (2006) 100-109.

[20] C.C. Decandio, E.R. Silva, I.W. Hamley, V. Castelletto, M.S. Liberato, V.X. Oliveira, C.L.P. Oliveira, W.A. Alves, Self-Assembly of a Designed Alternating Arginine/Phenylalanine Oligopeptide, Langmuir, 31 (2015) 4513-4523.

[21] N. Schmidt, A. Mishra, G.H. Lai, G.C.L. Wong, Arginine-rich cell-penetrating peptides, Febs Letters, 584 (2010) 1806-1813.

[22] A.A. Bogan, K.S. Thorn, Anatomy of hot spots in protein interfaces11Edited by J. Wells, Journal of Molecular Biology, 280 (1998) 1-9.

[23] D.M. Mitrea, R.W. Kriwacki, Phase separation in biology; functional organization of a higher order, Cell Communication and Signaling : CCS, 14 (2016) 1.

[24] M.S. Liberato, S. Kogikoski, E.R. da Silva, R.H. Silva, V.X. Oliveira, L.P. Scott, R.A. Ando, W.A. Alves, M.D. Coutinho-Neto, Self-Assembly of Arg-Phe Nanostructures via the SolidVapor Phase Method, J Phys Chem B, 117 (2013) 733-740.

[25] I. Bressler, J. Kohlbrecher, A.F. Thunemann, SASfit: a tool for small-angle scattering data analysis using a library of analytical expressions, Journal of Applied Crystallography, 48 (2015) 1587-1598.

[26] O.S. Makin, P. Sikorski, L.C. Serpell, CLEARER: a new tool for the analysis of X-ray fibre diffraction patterns and diffraction simulation from atomic structural models, Journal of Applied Crystallography, 40 (2007) 966-972.

[27] F.M. Winnik, Photophysics of Preassociated Pyrenes in Aqueous Polymer-Solutions and in Other Organized Media, Chemical Reviews, 93 (1993) 587-614. 
[28] A. Dehsorkhi, V. Castelletto, I.W. Hamley, Self-assembling amphiphilic peptides, Journal of Peptide Science, 20 (2014) 453-467.

[29] K. Kalyanasundaram, J.K. Thomas, Environmental effects on vibronic band intensities in pyrene monomer fluorescence and their application in studies of micellar systems, Journal of the American Chemical Society, 99 (1977) 2039-2044.

[30] V. Castelletto, I.W. Hamley, Self assembly of a model amphiphilic phenylalanine peptide/polyethylene glycol block copolymer in aqueous solution, Biophys Chem, 141 (2009) 169-174.

[31] L. Shimoni, J.P. Glusker, HYDROGEN-BONDING MOTIFS OF PROTEIN SIDE-CHAINS DESCRIPTIONS OF BINDING OF ARGININE AND AMIDE GROUPS, Protein Science, 4 (1995) 6574.

[32] C.L. Borders, J.A. Broadwater, P.A. Bekeny, J.E. Salmon, A.S. Lee, A.M. Eldridge, V.B. Pett, A structural role for arginine in proteins: Multiple hydrogen bonds to backbone carbonyl oxygens, Protein Science, 3 (1994) 541-548.

[33] A. Barth, The infrared absorption of amino acid side chains, Prog Biophys Mol Biol, 74 (2000) 141-173.

[34] H. Yang, S. Yang, J. Kong, A. Dong, S. Yu, Obtaining information about protein secondary structures in aqueous solution using Fourier transform IR spectroscopy, Nat. Protocols, 10 (2015) 382-396.

[35] D.M. Byler, H. SUSi, EXAMINATION OF THE SECONDARY STRUCTURE OF PROTEINS BY DECONVOLVED FTIR SPECTRA, Biopolymers, 25 (1986) 469-487.

[36] R.W. Woody, Aromatic side-chain contributions to the far ultraviolet circular dichroism of peptides and proteins, Biopolymers, 17 (1978) 1451-1467.

[37] N. Amdursky, M.M. Stevens, Circular Dichroism of Amino Acids: Following the Structural Formation of Phenylalanine, Chemphyschem, 16 (2015) 2768-2774.

[38] M.J. Krysmann, V. Castelletto, I.W. Hamley, Fibrillisation of hydrophobically modified amyloid peptide fragments in an organic solvent, Soft Matter, 3 (2007) 1401-1406.

[39] T. Zemb, P. Lindner, Neutrons, X-rays and light : scattering methods applied to soft condensed matter, 1st ed., Elsevier, Amsterdam ; Boston, 2002.

[40] B. Hammouda, Clustering in polar media, J Chem Phys, 133 (2010) 084901.

[41] G. Yuan, X. Wang, D. Wu, B. Hammouda, Structural analysis of dendrimers based on polyhedral oligomeric silsesquioxane and their assemblies in solution by small-angle neutron scattering: Fits to a modified two correlation lengths model, Polymer, 100 (2016) 119-125.

[42] B. Hammouda, A new Guinier-Porod model, Journal of Applied Crystallography, 43 (2010) 716-719.

[43] J. Teixeira, Small-Angle Scattering by Fractal Systems, Journal of Applied Crystallography, 21 (1988) 781-785.

[44] C.M. Sorensen, G.M. Wang, Size distribution effect on the power law regime of the structure factor of fractal aggregates, Phys Rev E, 60 (1999) 7143-7148.

[45] E.R. da Silva, W.A. Alves, V. Castelletto, M. Reza, J. Ruokolainen, R. Hussain, I.W. Hamley, Self-assembly pathway of peptide nanotubes formed by a glutamatic acid-based bolaamphiphile, Chemical Communications, 51 (2015) 11634-11637.

[46] B. Hammouda, SANS from homogeneous polymer mixtures: A unified overview, Polymer Characteristics, Springer Berlin Heidelberg, Berlin, Heidelberg, 1993, pp. 87-133.

[47] R.H. French, V.A. Parsegian, R. Podgornik, R.F. Rajter, A. Jagota, J. Luo, D. Asthagiri, M.K. Chaudhury, Y.-m. Chiang, S. Granick, S. Kalinin, M. Kardar, R. Kjellander, D.C. Langreth, J. Lewis, S. Lustig, D. Wesolowski, J.S. Wettlaufer, W.-Y. Ching, M. Finnis, F. Houlihan, O.A. von Lilienfeld, C.J. van Oss, T. Zemb, Long range interactions in nanoscale science, Reviews of Modern Physics, 82 (2010) 1887-1944.

[48] S. Prevost, S. Riemer, W. Fischer, R. Haag, C. Bottcher, J. Gummel, I. Grillo, M.S. Appavou, M. Gradzielski, Colloidal structure and stability of DNA/polycations polyplexes investigated by small angle scattering, Biomacromol, 12 (2011) 4272-4282. 
[49] J.C. Stroud, C. Liu, P.K. Teng, D. Eisenberg, Toxic fibrillar oligomers of amyloid- $\beta$ have cross- $\beta$ structure, Proceedings of the National Academy of Sciences, 109 (2012) 7717-7722.

[50] I.W. Hamley, S. Burholt, J. Hutchinson, V. Castelletto, E.R. da Silva, W. Alves, P. Gutfreund, L. Porcar, R. Dattani, D. Hermida-Merino, G. Newby, M. Reza, J. Ruokolainen, J. Stasiak, Shear Alignment of Bola-Amphiphilic Arginine-Coated Peptide Nanotubes, Biomacromol, 18 (2017) 141-149.

[51] I.W. Hamley, A. Dehsorkhi, V. Castelletto, S. Furzeland, D. Atkins, J. Seitsonen, J. Ruokolainen, Reversible helical unwinding transition of a self-assembling peptide amphiphile, Soft Matter, 9 (2013) 9290-9293.

[52] J.S. Pedersen, Analysis of small-angle scattering data from colloids and polymer solutions: modeling and least-squares fitting, Advances in Colloid and Interface Science, 70 (1997) 171-210.

[53] X.-c. Bai, G. McMullan, S.H.W. Scheres, How cryo-EM is revolutionizing structural biology, Trends in Biochemical Sciences, 40 (2015) 49-57.

[54] E.R. da Silva, M.N.M. Walter, M. Reza, V. Castelletto, J. Ruokolainen, C.J. Connon, W.A. Alves, I.W. Hamley, Self-Assembled Arginine-Capped Peptide Bolaamphiphile Nanosheets for Cell Culture and Controlled Wettability Surfaces, Biomacromol, 16 (2015) 3180-3190.

[55] K.L. Morris, A. Rodger, M.R. Hicks, M. Debulpaep, J. Schymkowitz, F. Rousseau, L.C. Serpell, Exploring the sequence-structure relationship for amyloid peptides, Biochem J, 450 (2013) 275-283.

[56] K.L. Morris, S. Zibaee, L. Chen, M. Goedert, P. Sikorski, L.C. Serpell, The Structure of Cross-beta Tapes and Tubes Formed by an Octapeptide, alpha $S$ beta 1, Angew Chem Int Edit, 52 (2013) 2279-2283.

[57] K. Morris, L. Serpell, From natural to designer self-assembling biopolymers, the structural characterisation of fibrous proteins \& peptides using fibre diffraction, Chem. Soc. Rev., 39 (2010) 3445-3453.

[58] D. Li, E.M. Jones, M.R. Sawaya, H. Furukawa, F. Luo, M. Ivanova, S.A. Sievers, W.Y. Wang, O.M. Yaghi, C. Liu, D.S. Eisenberg, Structure-Based Design of Functional Amyloid Materials, Journal of the American Chemical Society, 136 (2014) 18044-18051.

[59] I.W. Hamley, Peptide fibrillization, Angew Chem Int Ed Engl, 46 (2007) 8128-8147.

[60] S.B. Malinchik, H. Inouye, K.E. Szumowski, D.A. Kirschner, Structural analysis of Alzheimer's beta(1-40) amyloid: Protofilament assembly of tubular fibrils, Biophysical Journal, 74 (1998) 537-545.

[61] T.R. Jahn, O.S. Makin, K.L. Morris, K.E. Marshall, P. Tian, P. Sikorski, L.C. Serpell, The Common Architecture of Cross-beta Amyloid, Journal of Molecular Biology, 395 (2010) 717727.

[62] L.C. Serpell, J. Berriman, R. Jakes, M. Goedert, R.A. Crowther, Fiber diffraction of synthetic alpha-synuclein filaments shows amyloid-like cross-beta conformation, P Natl Acad Sci USA, 97 (2000) 4897-4902.

[63] M.F. Perutz, J.T. Finch, J. Berriman, A. Lesk, Amyloid fibers are water-filled nanotubes, $P$ Natl Acad Sci USA, 99 (2002) 5591-5595.

[64] E. Gazit, A possible role for pi-stacking in the self-assembly of amyloid fibrils, Faseb Journal, 16 (2002) 77-83.

[65] E. Gazit, Mechanisms of amyloid fibril self-assembly and inhibition, Febs J, 272 (2005) 5971-5978.

[66] C. Bechara, S. Sagan, Cell-penetrating peptides: 20 years later, where do we stand?, Febs Letters, 587 (2013) 1693-1702.

[67] S. Futaki, T. Suzuki, W. Ohashi, T. Yagami, S. Tanaka, K. Ueda, Y. Sugiura, Arginine-rich peptides. An abundant source of membrane-permeable peptides having potential as carriers for intracellular protein delivery, J Biol Chem, 276 (2001) 5836-5840.

[68] F. Chiti, C.M. Dobson, Protein misfolding, functional amyloid, and human disease, Annu Rev Biochem, 75 (2006) 333-366. 
[69] C.M. Dobson, Protein misfolding, evolution and disease, Trends in Biochemical Sciences, 24 (1999) 329-332.

[70] D.M. Fowler, A.V. Koulov, W.E. Balch, J.W. Kelly, Functional amyloid - from bacteria to humans, Trends in Biochemical Sciences, 32 (2007) 217-224.

[71] R.P. Friedrich, K. Tepper, R. Roznicke, M. Soom, M. Westermann, K. Reymann, C. Kaether, M. Fandrich, Mechanism of amyloid plaque formation suggests an intracellular basis of A beta pathogenicity, P Natl Acad Sci USA, 107 (2010) 1942-1947.

[72] L. Chen, N. Patrone, J.F. Liang, Peptide self-assembly on cell membranes to induce cell lysis, Biomacromolecules, 13 (2012) 3327-3333.

[73] P. Wadhwani, E. Strandberg, N. Heidenreich, J. Burck, S. Fanghanel, A.S. Ulrich, Selfassembly of flexible beta-strands into immobile amyloid-like beta-sheets in membranes as revealed by solid-state 19F NMR, Journal of the American Chemical Society, 134 (2012) 6512 6515. 

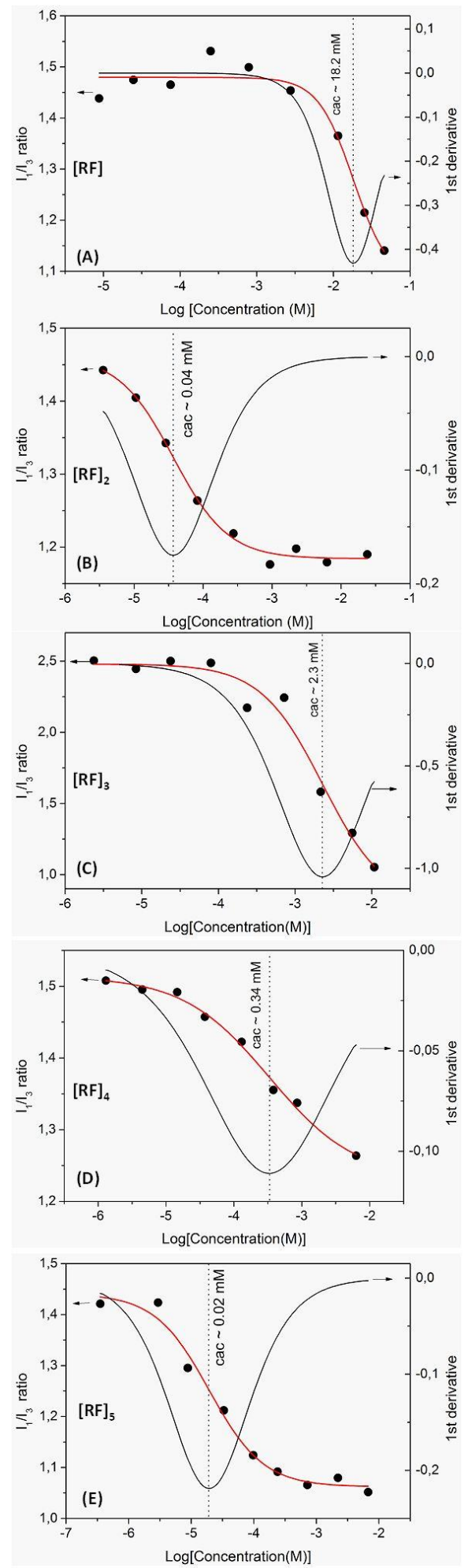

Figure 1: Behavior of pyrene $I_{1} / I_{3}$ ratio as a function log [peptide concentration]. Red lines are sigmoid fit functions (Equation 1). 

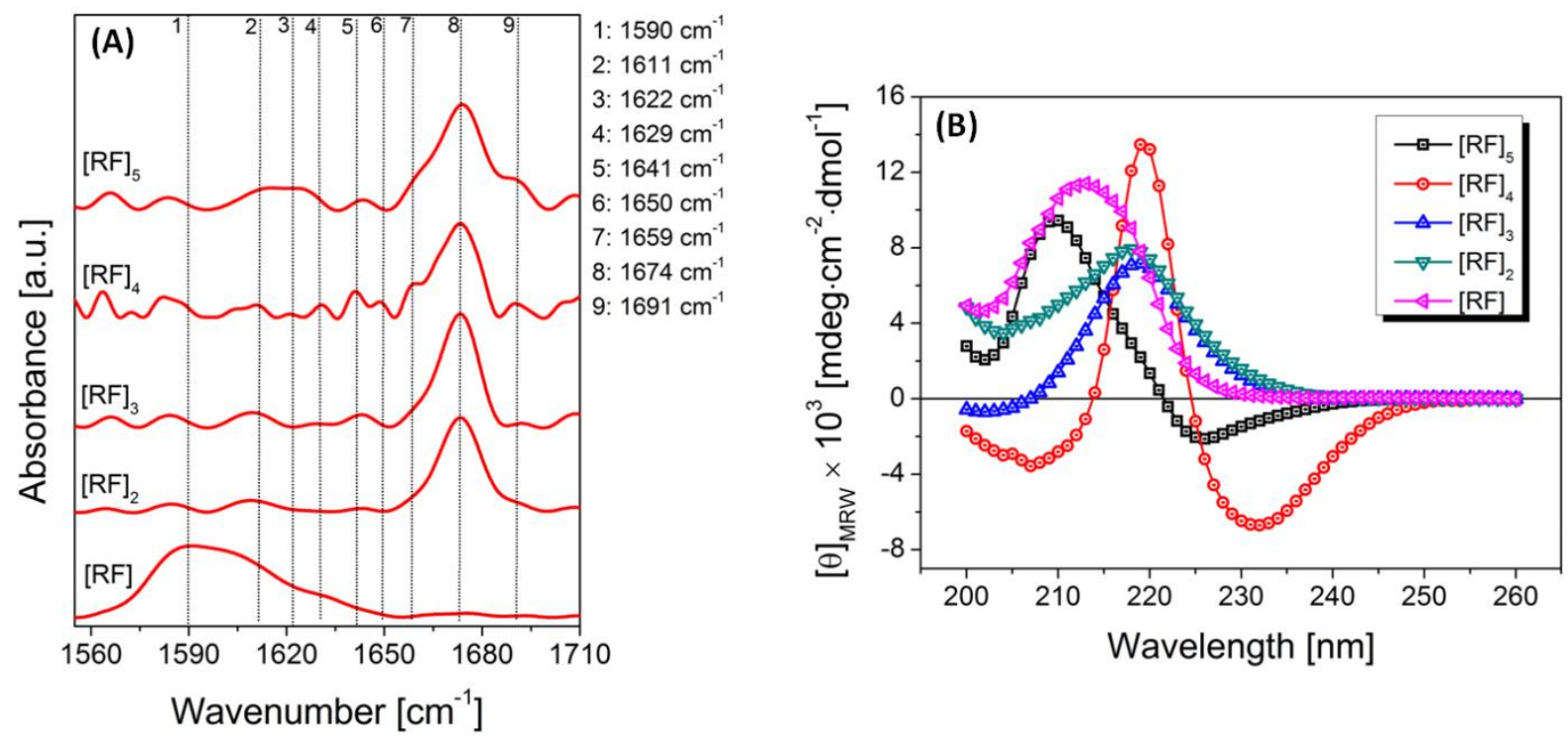

Figure 2: (A) FTIR and (B) CD spectra from $[\mathrm{RF}]_{1-5}$ solutions. 

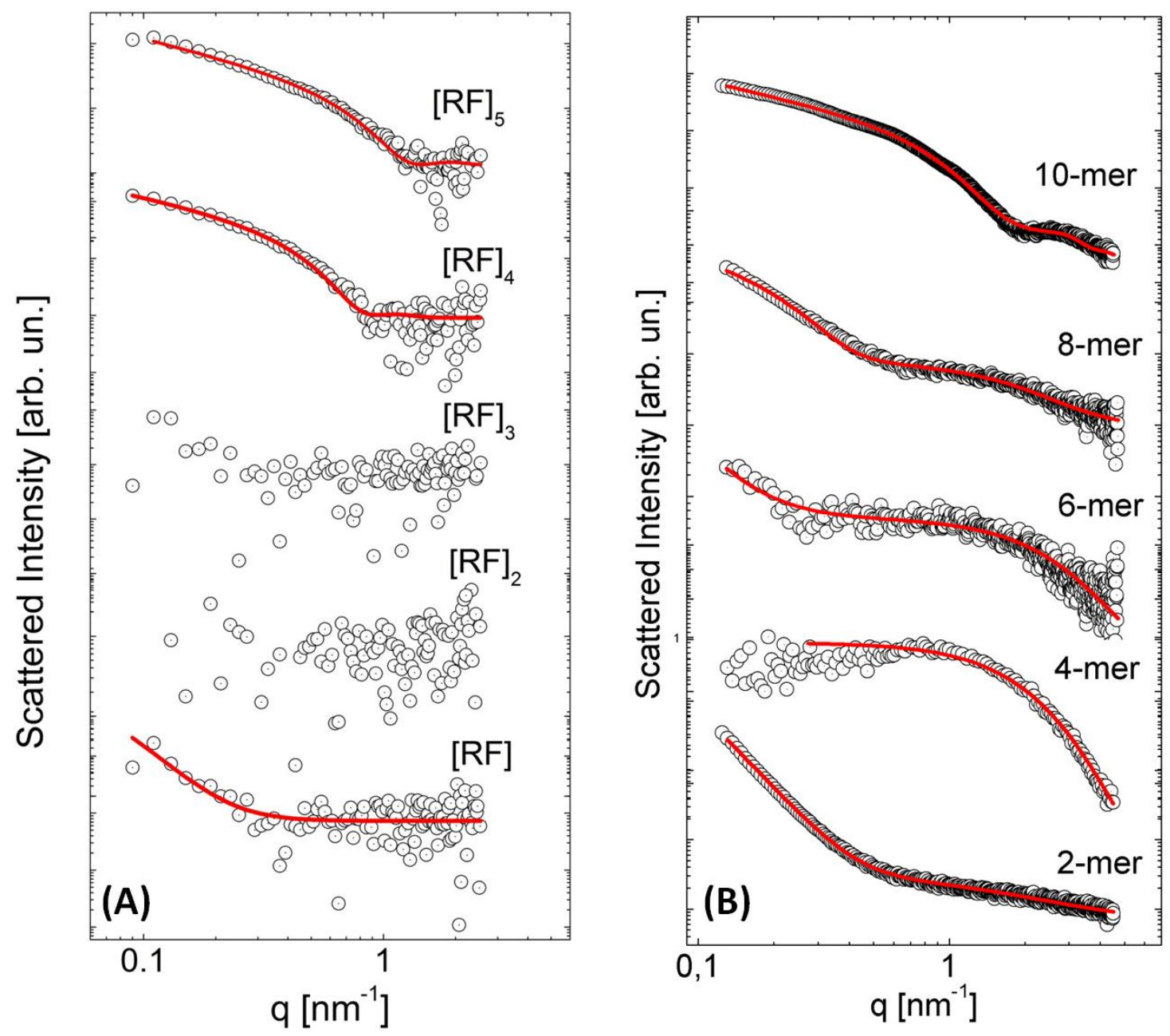

Figure 3: Small-angle neutron (A) and X-ray (B) scattering profiles from peptide solutions containing [RF] units at $c a .30 \mathrm{mM}$. Data have been fitted using shape-dependent models, described in the text, revealing the presence of small oligomers in coexistence with high molecular-weight structures. 

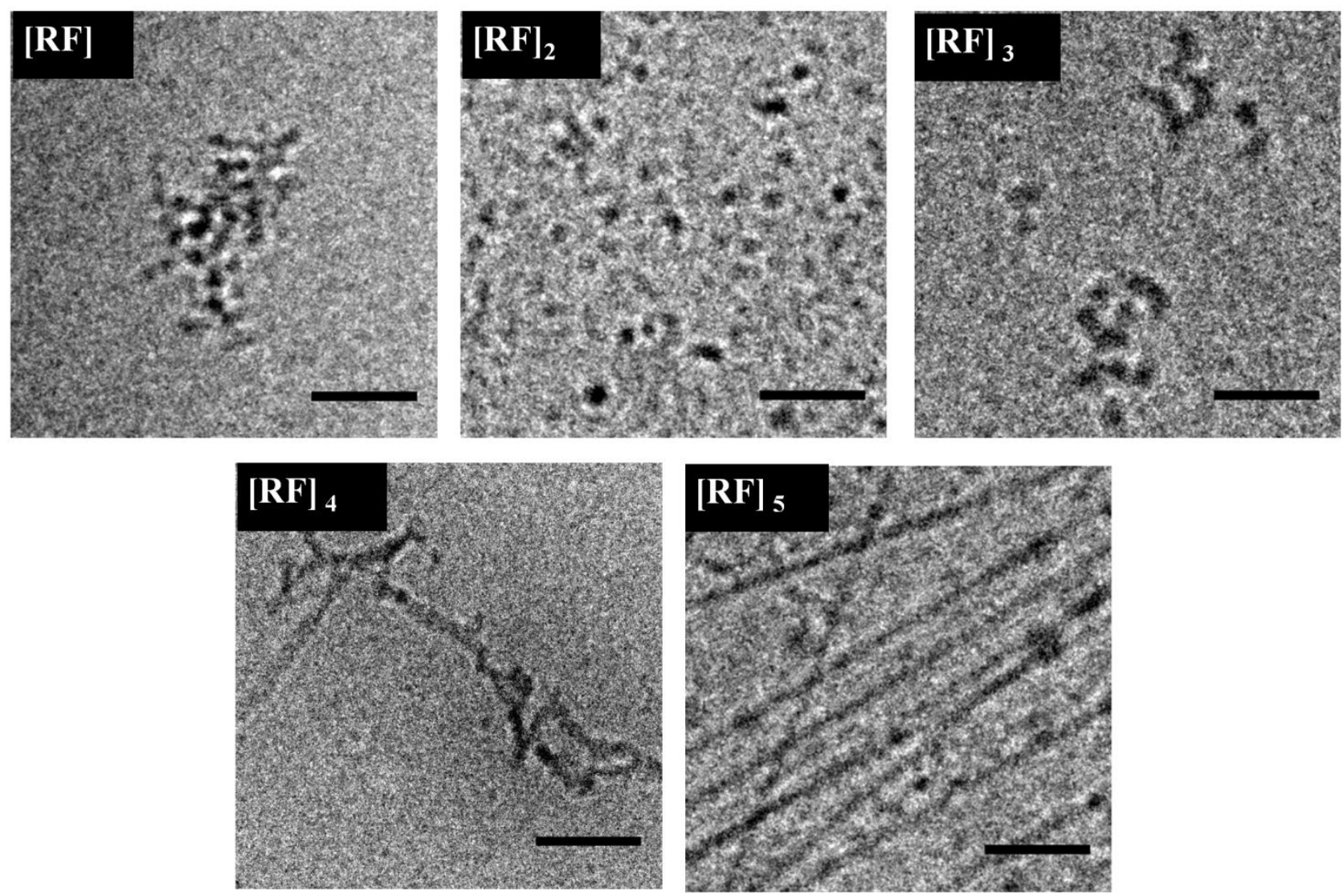

Figure 4: Cryo-EM images from vitrified specimens revealing the presence of different nanostructures according to the length of the peptide in solution. Scale bars: $50 \mathrm{~nm}$. 

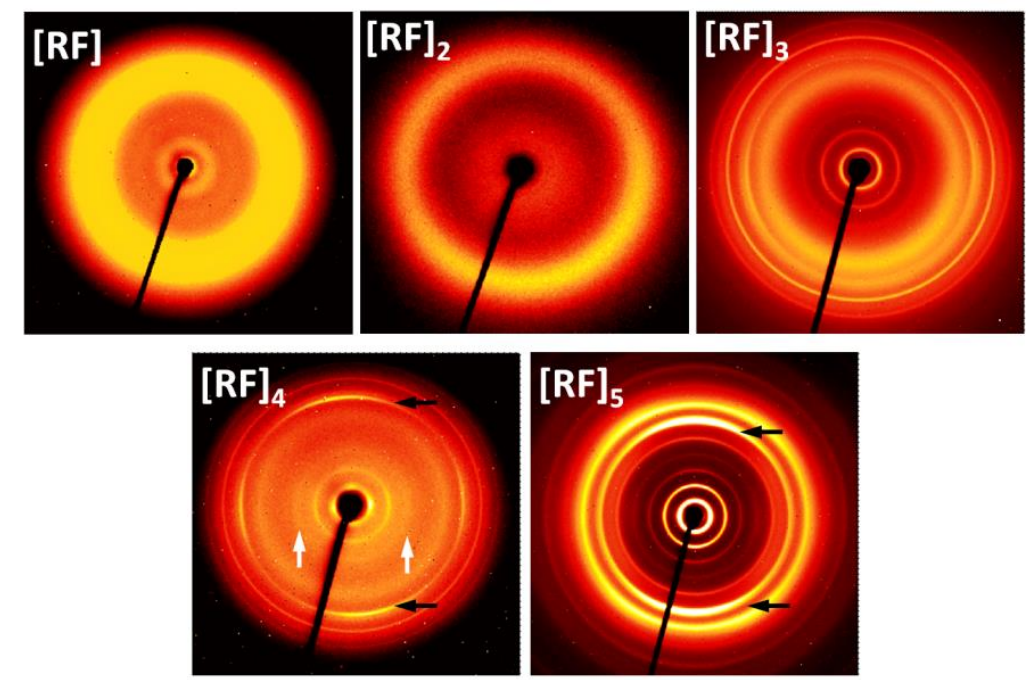

(A)

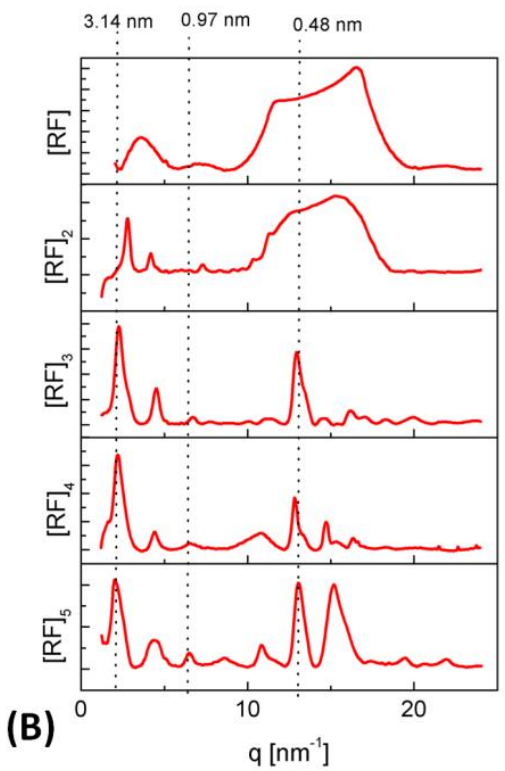

Figure 5: (A) Two dimensional X-ray diffraction patterns from partially-oriented stalks prepared from dried peptide solutions. Black arrows for $[R F]_{4}$ and $[R F]_{5}$ patterns indicate meridional reflections associated to periodicity $D=0.48 \mathrm{~nm}$ arising from perpendicularly-oriented $\beta$-strands, whereas white arrows indicate equatorial reflections related to $\beta$-sheet separation. (B) Intensity profiles obtained by radial averaging of the patterns exhibited in (A). Black lines are a guide for the eyes indicating distances corresponding either to separation between $\beta$-sheets running along fiber axis $(1 \mathrm{~nm})$ or to separation between hydrogen-bound $\beta$-strands $(0.48 \mathrm{~nm})$. 


\section{C6}

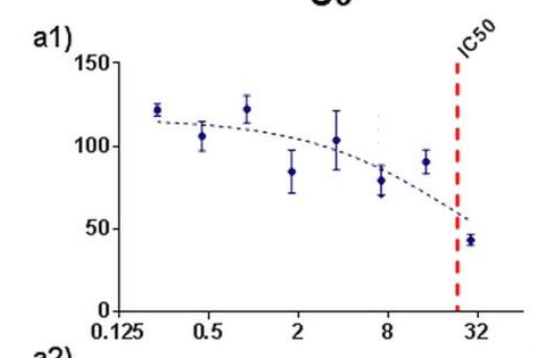

a2)

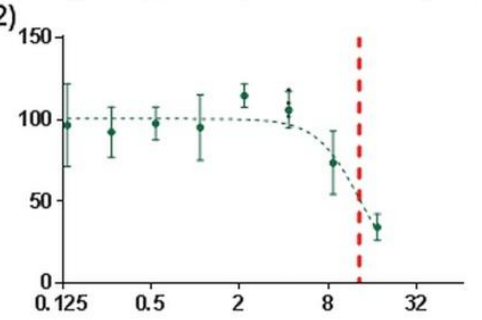

a3)

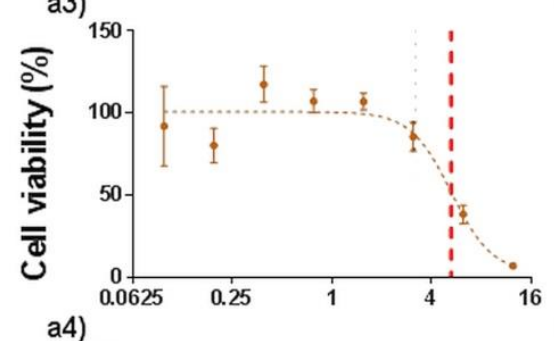

a4)

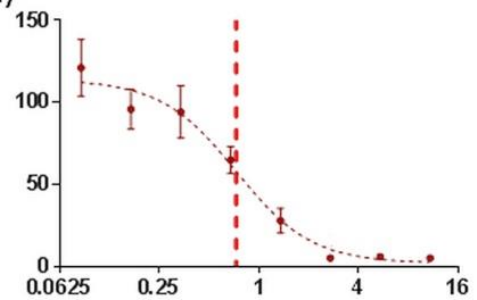

a5)

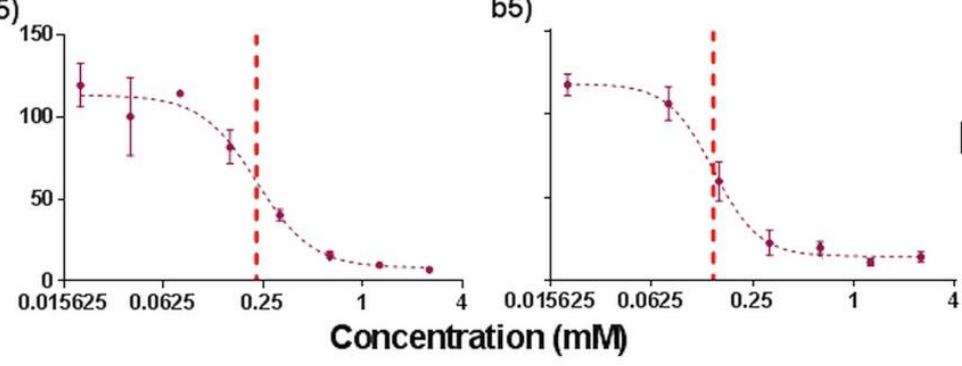

b1)

RAW264.7

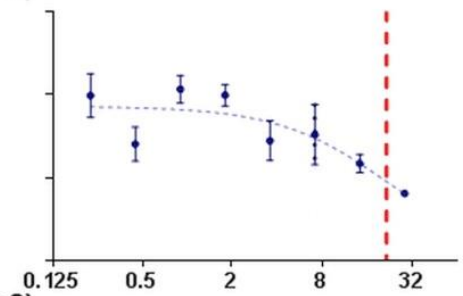

RF

b2)

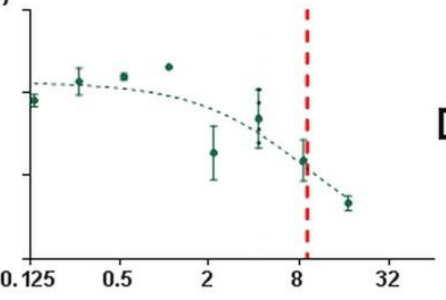

$[\mathrm{RF}]_{2}$

b3)

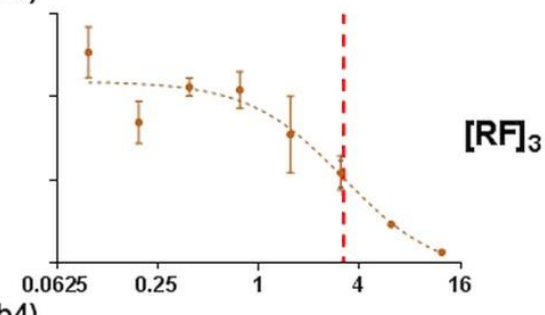

b4)

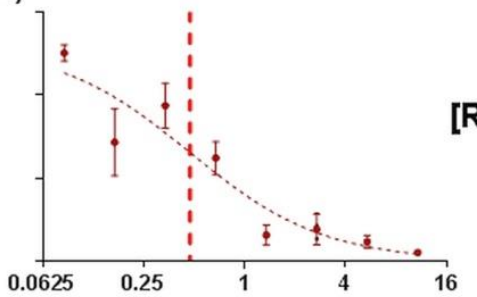

$\left[\mathrm{RF}_{4}\right.$

$\left[\mathrm{RF}_{5}\right.$

Figure 6: Cytotoxicity profiles of $[R F]_{1-5}$ in (a) C6 and (b) RAW264.7 cells. Data is plotted as mean \pm s.e.m., $\mathrm{n}=4$ ( 2 independent tests). IC50 of each $[\mathrm{RF}]_{\mathrm{n}}$ obtained from two cell lines were compared with unpaired $t$-tests, in which no differences were noted (See Table 2). Dotted lines along with experimental data correspond to the non-linear fitting to the variable slope sigmoid equation for each data set. IC50 values are marked with red vertical dashed line. 

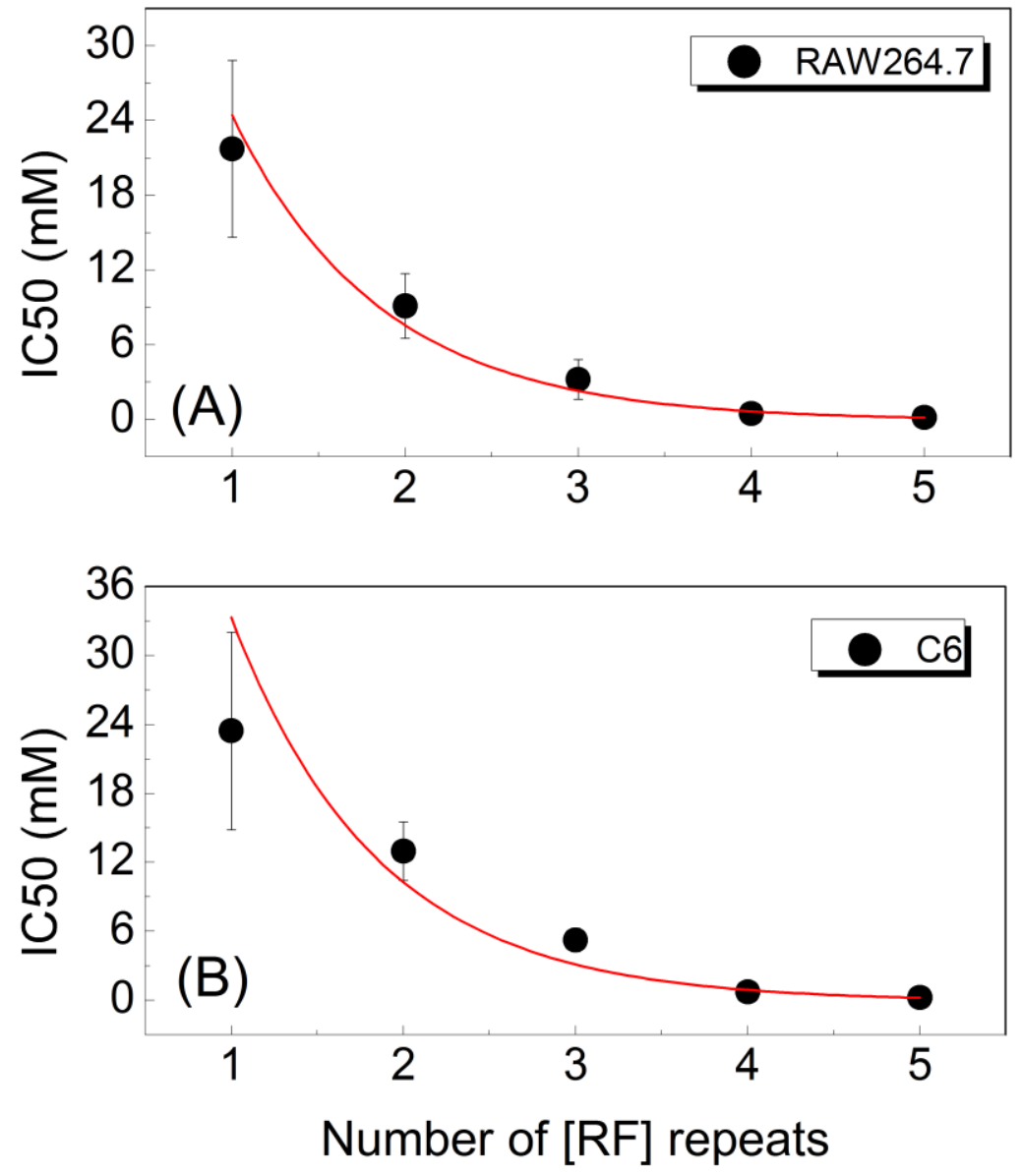

Figure 7: IC50 as a function of the number of repeats of [RF]. Exponentially decaying profiles of IC50 values for (A) RAW264.7 and (B) C6 cell lines. 


\section{GRAPHICAL ABSTRACT}

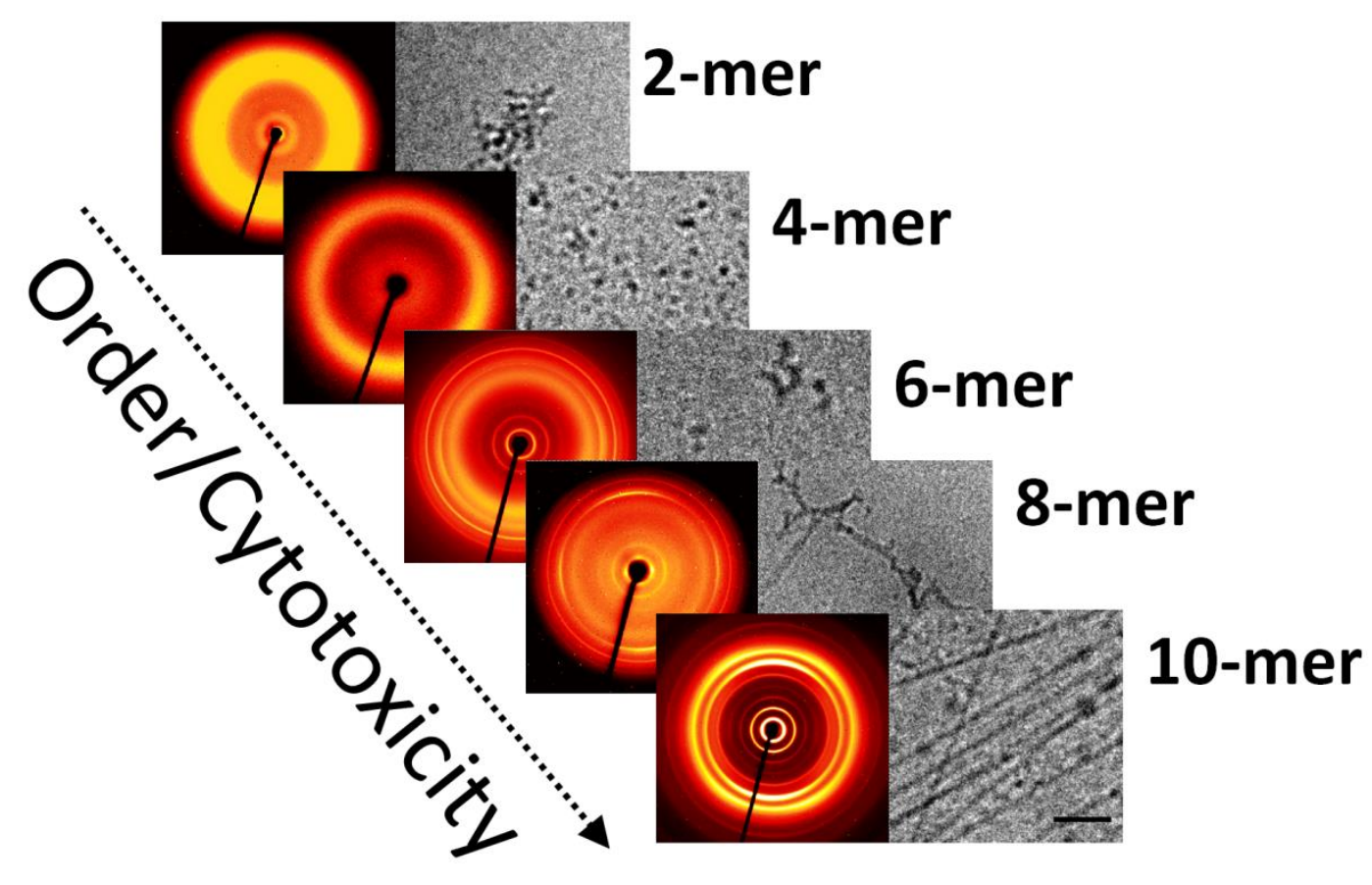

\section{Highlights:}

- Progressive crystalline order is found upon sequence length in $[R F]_{n}$ peptides;

- Amyloid- $\beta$ features are found in 8-mer and 10 -mer sequences;

- Order correlate with cell death, suggesting that structure matters for cytotoxicity. 